\title{
Radiotherapy and ophthalmology: time for a friendly re-acquaintance
}

Many ophthalmologists expect radiotherapy to be accompanied by late morbidity and therefore reserve it for desperate situations. The radiation tolerance of ocular and orbital structures is now well appreciated, ${ }^{12}$ and many sequelae of radiotherapy may be prevented by careful radiation dose and modern techniques. Ophthalmologists should be aware that there is a tenfold difference in dose between the cataract threshold and the dose required to harm the retina by conventional external beam radiation.

\section{Superficial $x$ ray therapy}

Superficial $x$ ray therapy is curative for basal cell and squamous carcinomas of the lids and, with careful fractionation, ectropion, nasolacrimal duct stenosis, and other complications are rarely encountered; the globe is protected by lead 'contact lens' shields placed behind the lids. Conjunctival malignancy (and pterygia) responds well to $\beta$-therapy from strontium plaques - made 'double sided' to treat malignancy involving the tarsal as well as bulbar conjunctiva; the $\beta$-rays do not penetrate to the lens in cataractogenic doses. Haemangiomas of the lids and conjunctiva regress with radiotherapy, ${ }^{3}$ as does the conjunctival Kaposi sarcoma associated with AIDS. ${ }^{+}$

Lacrimal gland malignancy may be improved by radiotherapy after surgery, but this does not compensate for radical surgical clearance where this is possible.

\section{Intraocular uses}

Low dose radiotherapy may be beneficial in certain benign ocular conditions. Juvenile xanthogranuloma of the iris is extremely radiosensitive, ${ }^{6}$ and diffuse choroidal haemangiomas also respond well. The dose is delivered by a lenssparing technique developed for retinoblastoma (see below). ${ }^{37}$

For localised intraocular tumours the now standard use of iodine- 125 and ruthenium-106/rhodium-106 ocular plaque brachytherapy has reduced the dose to the operator, and such plaques are replacing the cobalt plaque in both retinoblastoma and melanoma work. The pure $\beta$-emissions of ruthenium (with their intense dose to the tumour base, causing infarction) may have further advantages in melanoma therapy. The proton beam data on ocular melanomas look impressive ${ }^{8}$; this too may owe at least some of its effect to damage to tumour vasculature. ${ }^{9}$ However, the proton work needs to be compared prospectively with conventional plaque therapy. There are good data suggesting that orbital radiotherapy reduces the local relapse rate $^{10}$ after extrascleral extension of a melanoma.

External beam radiotherapy remains the basis of treatment when focal methods fail to control the spread of retino-

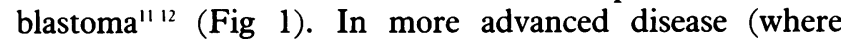
enucleation of an only eye is unacceptable to parents), induction chemotherapy followed by radiotherapy is under intense study with good results.

Other globe malignancies that respond well to radiation are choroidal involvement by leukaemia and metastases from solid cancer. In leukaemic children receiving prophylactic cranial irradiation, the back of the eye receives some radiation and this may explain the lower ocular relapse rate. ${ }^{13}$ Choroidal metastases (especially from breast carcinoma) may be associated with cerebral metastases, and thus a computed tomography scan is performed before recommending radiotherapy to the eye alone. Similarly, ocular lymphoma is also associated with an increased incidence of intracerebral disease.

\section{Orbital disease}

Benign disease of the orbit may respond to low dose therapy now that sophistication of techniques allow protection of the anterior chamber, lacrimal gland, and lens. Thus Langerhans cell histiocytosis (histiocytosis $\mathrm{X}$ ) of the orbit is one example, ${ }^{15}$ and orbital haemangioma may also benefit. ${ }^{37}$

The management of Graves' ophthalmology generates considerable debate. ${ }^{16}{ }^{17}$ Radiotherapy has been advocated for many years ${ }^{18}$ but only recently have modern methods obviated treatment related morbidity. ${ }^{1519}$ Thus, current radiation methods allow effective treatment for steroid resistant disease - particularly with optic nerve compression, exposure keratitis, and painful orbitopathy. Recent analyses showed that surgical decompression or radiotherapy were effective but that surgical decompression gave a slightly greater decrease in proptosis; however ocular movements were better assisted by radiotherapy. ${ }^{2021}$ This last observation, when coupled with the safe track record of the current technique, may increase the indications for radiotherapy. However, other authors have not found such improvements in ocular motility. 2223

Orbital pseudotumours are sensitive to low dose radio-



Figure 1 Child on 'set-up' for bilateral lens-sparing retinal radiotherapy (for bilateral retinoblastoma) by this technique. 

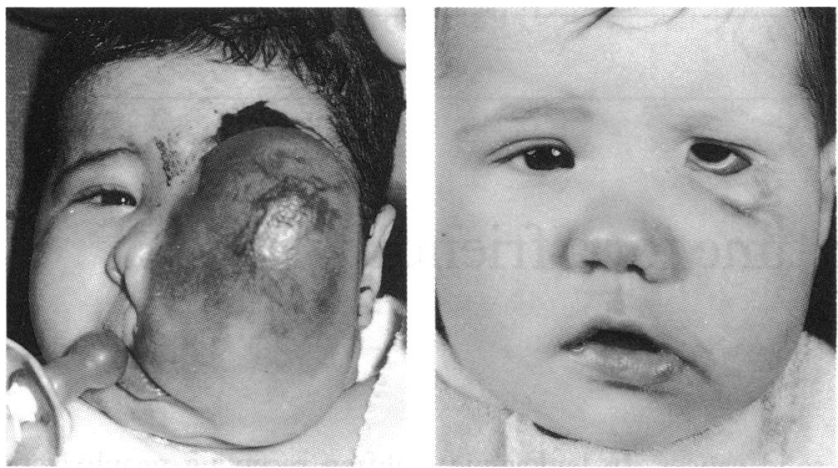

Figure 2 Facial rhabdomyosarcoma of childhood. Left: before treatment. Right: after a modern, aggressive chemoradiotherapy protocol.

therapy and midline ocular structure shielding is practised routinely. ${ }^{2+25}$ The patient with benign disease may be warned of the carcinogenic potential, which is of the order of magnitude of $10^{-4}$

True orbital lymphomas contain a highly curable group of extranodal non-Hodgkin's lymphomas. The high grade tumours (approximately 20\%), and those with extraorbital extension, require chemotherapy first. The majority of lymphomas are low grade B tumours confined to the orbit; and relatively low dose radiotherapy is curative. ${ }^{26}$

Orbital sarcoma in childhood is usually embryonal rhabdomyosarcoma with a good prognosis (following a chemoradiotherapy programme). These tumours are usually confined to the orbit and such patients have a more than $80 \%$ survival rate on current treatment protocols. Late effects due to radiation have recently been reported ${ }^{27}$ with a radiation dose prescription of 5000-6000 cGy in $200 \mathrm{cGy}$ fractions. In current protocols the total dose is $4000-4500 \mathrm{cGy}$ in lower daily dose fractions and the late sequelae may be confidently predicted to be lower. Alveolar histology (approximately $10 \%$ ) or extraocular spread may demand the higher dose (Fig 2). Adult sarcomas of the orbit are more resistant, and surgery and radiotherapy are the mainstays of treatment, with continued debate as to whether adjunctive chemotherapy has a role. Equally debated is the order: preoperative radiotherapy (to facilitate surgical excision with clear

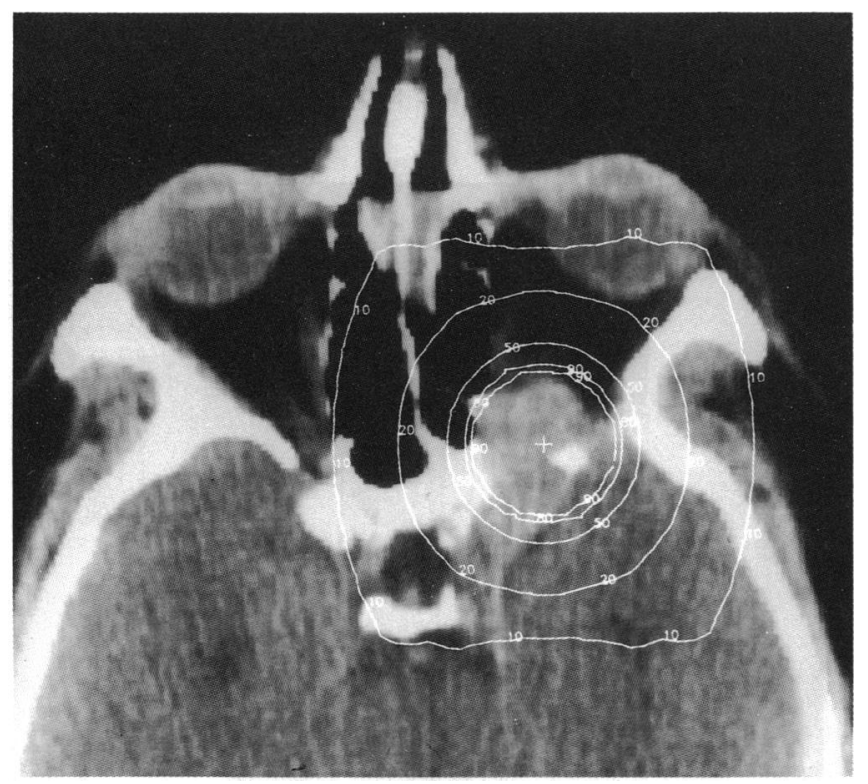

Figure 3 Transaxial computed tomography $(C T)$ scan cut showing recurrence of prolactinoma (following trans-sphenoidal pituitary surgery and radiotherapy) growing through the optic canal into the orbit. Using modern, stereotactically mapped, focal radiotherapy (St Bartholomew's method) the lesion was irradiated to obliterative dose. The patient was already blind in the ipsilateral eye, but the chiasm did not receive a high (re-treatment) dose. Subsequent CT scans show progressive disappearance of the prolactinoma. margins) versus postoperative radiotherapy (to sterilise microscopic disease left behind).

Optic nerve gliomas receive radiotherapy if they extend back to the chiasm with deteriorating vision. Optic nerve meningiomas in adults have also been treated by radiotherapy, with anecdotal cases of improved vision after carefully fractionated radiotherapy. ${ }^{28} 29$

Occasionally, difficult tumours occur at the back of the orbit, extending through the optic canal intracranially. A recently introduced focal stereotactic external beam radiotherapy method is now available to deliver extremely high doses to streotactically mapped lesions anywhere in the cranium; the isodoses fall off very sharply at the target perimeter. Of proved use for intracerebral AVMs this technique may be useful in orbital disease. Using the St Bartholomew's focal method, we have recently treated a prolactinoma (resistant to bromocriptine and previous external beam radiotherapy) which had extended from the pituitary fossa through the optic canal to the back of the orbit. A very high treatment dose was delivered and the tumour has regressed but the critical point is that the abutting (and previously irradiated) optic chiasm received less than $20 \%$ of the treatment dose (Fig 3 ). Such technology has also been used for focal treatment of choroidal melanoma in lieu of protons ${ }^{30}$ and will have further applications for locally aggressive tumours, particularly at the orbital apex.

In summary, modern radiotherapy has much to offer patients with ocular problems. Knowledge of the radiobiological tolerance of normal ocular structures, enhanced technical precision, and better appreciation of limits of usefulness and morbidity pitfalls have all led to improved therapeutic ratios (success: morbidity).

PN PLOWMAN

Department of Radiotherapy,

St Bartholomew's Hospital,

West Smithfield, London ECl

1 Parsons JT, Fitzgerald CR, Hood CI, et al. The effects of irradiation on the eye and optic nerve. Int $\mathcal{F}$ Radiat Oncol Biol Phys 1983; 9: 609-22.

2 Harnett AN, Hungerford JL. Ocular morbidity in radiotherapy. In: Plowman PN, McElwain TJ, Meadow A, eds. Complications of cancer management. Oxford: Butterworth-Heinemann, 1991, 361-78.

3 Plowman PN, Harnett AN. Radiotherapy in benign orbital disease, I: Complicated ocular angiomas. Brf Ophthalmol 1988; 72: 286-8.

4 Glynne Jones R, Hungerford JL, Johnson MA, Plowman PN. Epidemic Kaposi's sarcoma of the conjunctiva: considerations for radiotherapy.

5 Wright JE, Rose GE, Garner A. Primary malignant neoplasms of the lacrimal gland. [Submitted.]

Macleod P. Case report: juvenile xanthogranuloma of the iris managed with superficial radiotherapy. Clin Radiol 1986; 37: 295-6.

Dutton S, Plowman PN. Paediatric haemangiomas: the role of radiotherapy. BrF Radiol 1991; 64: 261-9.

8 Munzenrider JE, Gragoudas ES, Seddon JM, Sisterson J, McNulty P, Birnbaum S, et al. Conservative treatment of uveal melanoma: probability of eye retination after proton treatment. Int $\mathcal{F}$ Radiat Oncol Biol Phys 1988; 15: $553-8$.

9 Seddon JM, Gragoudas ES, Albert DM. Ciliary body and choroidal melanomas treated by proton beam irradiation. Arch Ophthalmol 1983; 101: 1402-8.

10 Hykin PG, McCartney AC, Plowman PN, Hungerford JL. Post enucleation orbital radiotherapy for the treatment of malignant melanoma of the choroid with extra-scleral extension. $B r 7$ Ophthalmol $1990 ; 74: 36-9$

11 Schipper J. Retinoblastoma - a medical and experimental study. PhD Thesis (Proefschrift), Univ Utrecht, 1980.

12 Harnett AN, Hungerford JL, Lambert G, et al. Improved external beam radiotherapy for the treatment of retinoblastoma. Br $\mathcal{F}$ Radiol 1987; 60: radiotherapy for the treatment of retinoblastoma. Br $\mathcal{F}$ Radiol 1987; 60:

13 Harnett AN, Hirst A, Plowman PN. The eye in acute leukaemia I: dosimetric analysis in cranial radiation prophylaxis. Radiother Oncol 1987; 10: 195 202 .

14 Harnett AN, Plowman PN. The eye in acute leukaemia II: the management of solitary anterior chamber relapse. Radiother Oncol 1987; 10: 203-7.

15 Harnett AN, Doughty D, Hirst A, Plowman PN. Radiotherapy in benign orbital disease II: Oph, Hirst A, Plowman PN. Radiotherapy in benign Brf Ophthalmol 1988; 72: 289-92.

16 Weetman AP. Thyroid associated eye disease: pathophysiology. Lancet 1991; 338: $25-8$.

17 Fells $P$. Thyroid associated eye disease: clinical management. Lancet $1991 ; 338$ : 29-32.

18 Jones AE. Orbital $x$ ray therapy for progressive exophthalmos. Br 7 Radiol 1951; 24: 637-46.

19 Donaldson SS, Bagshaw MA, Kriss JP. Supervoltage orbital radiotherapy for Graves' ophthalmology. F Clin Endocrinol Metab 1973; 37: 276-85.

20 Fells P, Rosen P, Pickard B, Plowman N. Radiotherapy or surgery for orbital decompression in dysthyroid eye disease. Proc Br Ophthalm Soc Mtg

21 Lawson JWM, Rosen PH, McGarry B, Kousoilides L, Lightman S, Fells P.

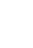
$\vec{z}$

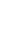


et al. Changes in ocular motility following radiotherapy for dysthyroid eye disease. Proc Eur Strabismolog Assoc (Crete) 1991 [Abstract]

22 Pigeon P, Orgiazzi J, Berthezene F, Gerard JP, Haguenauer JP, Mornex $R$. High voltage orbital radiotherapy and surgical orbital decompression in the management of Graves' ophthalmopathy. Horn Res 1987; 26: 17223 Ten

eng CS, Crombie AL, Hall R, Ross WM. An evaluation of supervoltage Craves' ophthalmopathy. Clin Endocrinol 1980; 13: $545-5$

24 Sergott RC, Glaser JS, Charyulu K. Radiotherapy for idiopathic inflammatory .

25 Orcutt JC, Garner A, Henk JM, Wright JE. Treatment of idiopathic inflammatory orbital pseudotumours by radiotherapy. Brf Ophthalmol 1983; 67: 570-4. 26 Bessell EM, Henk JM, Wright JE, Whitelock RAF. Orbital and conjunctival lymphoma treatment and prognosis. Radiother Oncol 1988; 13: 237-44.

27 Heyn R, Rate effects of therapy in orbital rhabdomyosarcoma in children. Cancer 1986; 57 : (7) 38

28 Kennerdell JS, Maroon JC, Malton M, Warren FA. The management of optic sheath meningioma. Am $\mathcal{F}$ Ophthalmol 1988; 106: 450-7.

29 Deutsch M. Personal communication. radiosurgery in the treatment of eye melanoma. Neurol Res 1987; 9: 142-6. 